\title{
Relationship between mean platelet volume and intensive care unit requirement in COVID-19 patients
}

\author{
(1)Rohat Ak ${ }^{1}$, @Fatih Doğanay ${ }^{2}$ \\ ${ }^{1}$ Kartal Dr. Lütfi Kurdar City Hospital, Department of Emergency Medicine, İstanbul, Turkey \\ ${ }^{2}$ Edremit Public Hospital, Department of Emergency Medicine, Balıkesir, Turkey
}

Cite this article as: Ak R, Doğanay F. Relationship between mean platelet volume and intensive care unit requirement in COVID-19 patients. J Health Sci Med 2021; 4(3): 353-357.

\begin{abstract}
Objective: Our primary aim in this study is to examine the relationship between the mean platelet volume (MPV) and the intensive care unit (ICU) requirement in patients with 2019 coronavirus disease (COVID-19). The secondary aim of the study is to investigate the relationship between age and the ICU requirement.

Material and Method: This retrospective observational study was conducted with patients who were diagnosed with COVID-19 in the emergency department of a tertiary hospital. The relationship between the ICU requirement and MPV was evaluated using the Mann-Whitney U test. ROC analysis was performed to determine the predictive accuracy of the 8.3 cut-off value of MPV in those younger than 58 years old patients. CHAID analysis was used as the decision tree method in analyzing the data. The relationship between ICU requirement and MPV were evaluated.

Results: There were 711 patients included in this study. The median age of the population was 64 (49-76). According to the CHAID analysis, the study population was divided into 2 classes as those who aged 58 years or younger (Younger Group) and those who older than 58 years (Older Group), and the relationship between the 8.3 threshold value of MPV and the ICU requirement was analyzed. For the Younger group, a significant difference was found in terms of ICU requirement based on the 8.3 threshold value of MPV.

Conclusion: Advanced age, high MPV and PLT values in COVID-19 patients, are associated with the ICU requirement. The 8.3 threshold value of MPV can be used as one of the parameters determining the ICU requirement in relatively young patients. In the geriatric age group, it is not beneficial to use MPV measurement to assign the ICU requirement. Multi-center studies with a large number of patients are needed to present the strength of the results of our study more clearly.
\end{abstract}

Keywords: COVID-19, mean platelet volume, intensive care unit, platelet count, CHAID

\section{INTRODUCTION}

In December 2019, a series of unknown cases of acute respiratory disease occurred in Wuhan, the capital of China's Hubei province. It has been shown that the disease is caused by "severe acute respiratory syndrome coronavirus 2" (SARS-CoV-2). On February 11, 2020, the World Health Organization (WHO) has officially named the disease as 2019 coronavirus disease (COVID-19). The disease rapidly spread from Wuhan to other regions around the world (1-3).

Most patients show mild symptoms, but some patients (especially those who elderly and/or patients with comorbidities) experience severe symptoms. In these patients, following does occur rapidly: acute respiratory failure, acute respiratory distress syndrome (ARDS), septic shock, metabolic acidosis and coagulation disorders. Patients with COVID-19 and severe pneumonia have a worse prognosis than patients with the milder type. Therefore, early recognition of risk factors is very important for the treatment and prognosis of patients (4-6).

Platelets play an important role in inflammation and coagulation procedure. Activated platelets secrete a large number of substances that belong to the main factors of inflammation. Mean platelet volume (MPV) has been recognized as a key marker of platelet activation. MPV is a useful prognostic indicator for critically ill patients $(7,8)$.

Our primary aim in this study is to examine the relationship between MPV values and intensive care unit (ICU) requirement in COVID-19 patients. The secondary aim of the study is to investigate the relationship between age and the ICU requirement. 


\section{MATERIAL AND METHOD}

This retrospective observational study was carried out in the ED of a tertitary hospital between September 1, 2020 and November 1, 2020. The study was carried out with the permission of Research Ethics Committee of Kartal Dr. Lütfi Kurdar City Hospital (Date: 29.03.2021, Decision No: 2021/514/198/28). This study was carried out in accordance with the principles of the Declaration of Helsinki.

All COVID-19 patients over the age of 18 who were hospitalized between September 1, 2020 and December 1,2020 were included in this study. The diagnosis of COVID-19 was determined based on the World Health Organization (WHO) guidelines. This study includes only patients who had positive results in the real-time Reverse Transcriptase-Polymerase Chain Reaction (RTPCR) test of nasal and pharyngeal swab samples (9). The digital records of the Hospital Information Management System was used to collect data. For the patients who were included this study, their age; gender; vital signs; chronic diseases; and laboratory tests were recorded on a format the time of application to the emergency department.

\section{Statistical Analysis}

Statistical analyzes were performed with IBM SPSS Statistics 26 (SPSS) and MedCalc Version 19 software. Normality was tested to examine the relationship between variables and ICU groups. Age, PLT (platelet), MPV (mean platelet volume), PLT/MPV data could not meet the normality assumption.

Comparisons of groups, Mann-Whitney U test was used for quantitative data, reported as median and 25th-75th. Chi-square test was used for qualitative data and reported as frequency and percentage.

CHAID analysis, a decision tree method, was used to test the hypothesis that the MPV variable affects the requirement for ICU in relation to age. CHAID analysis has advantages such as modeling using continuous and/ or categorical variables and describing the relationship network of variables. CHAID analysis can provide treeshaped, easy-to-understand outputs by detailing the relationships between independent variables. Due to the advantages it provides, CHAID analysis is used for data analysis in many disciplines (10).

In order to investigate in detail the diagnostic accuracy of the MPV 8.3 value for the ICU requirement, a receiver operating characteristic (ROC) analysis was performed with using the DeLong method (11). The area under the curve (AUC), sensitivity, specificity, PPV, NPV, and Youden's J index (YJI) were calculated. YJI and AUC were calculated to evaluate predictive accuracy of MPV 8.3 cutoff in terms of ICU need.

Statistical significance was based on a value of $\mathrm{p}<0.05$.

\section{RESULTS}

The study was continued with the data of 711 patients after the exclusion criteria were applied. While 596 patients did not need ICU, 115 patients required ICU. The patients who needed ICU requirement were 62 males and 53 females. There was no significant difference between the genders in terms of ICU requirement $(\mathrm{p}=0.442)$.

The median age of the population included in the study was 64 (49-76). The median age of the group with ICU requirement was 75 (65-81), while that of the group that did not need ICU was 61 (47-74). When evaluated in terms of age, there was a significant difference between the groups determined according to ICU requirement $(\mathrm{p}<0.001)$ (Table 1).

\begin{tabular}{|c|c|c|c|c|c|c|c|c|}
\hline \multirow{2}{*}{ 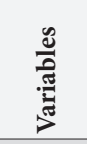 } & \multirow{2}{*}{ 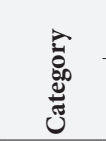 } & \multicolumn{2}{|c|}{ IU } & \multicolumn{2}{|c|}{ ICU } & \multicolumn{2}{|c|}{ Total } & \multirow{2}{*}{ Sig. } \\
\hline & & n & $\%$ & $\mathbf{n}$ & $\%$ & $\mathbf{n}$ & $\%$ & \\
\hline \multirow{2}{*}{ Sex } & Male & 298 & $50.0 \%$ & 62 & $53.9 \%$ & 360 & 50.6 & \multirow{2}{*}{0.442} \\
\hline & Female & 298 & $50.0 \%$ & 53 & $46.1 \%$ & 351 & 49.4 & \\
\hline \multirow{2}{*}{ COPD } & No & 566 & $95.0 \%$ & 103 & $89.6 \%$ & 669 & $94.1 \%$ & \multirow{2}{*}{0.024} \\
\hline & Yes & 30 & $5.0 \%$ & 12 & $10.4 \%$ & 42 & $5.9 \%$ & \\
\hline \multirow{2}{*}{ DM } & No & 438 & $73.5 \%$ & 81 & $70.4 \%$ & 519 & $73.0 \%$ & \multirow{2}{*}{0.499} \\
\hline & Yes & 158 & $26.5 \%$ & 34 & $29.6 \%$ & 192 & $27.0 \%$ & \\
\hline \multirow{2}{*}{ HT } & No & 394 & $66.1 \%$ & 70 & $60.9 \%$ & 464 & $65.3 \%$ & \multirow{2}{*}{0.280} \\
\hline & Yes & 202 & $33.9 \%$ & 45 & $39.1 \%$ & 247 & $34.7 \%$ & \\
\hline \multirow{2}{*}{$\mathrm{CHF}$} & No & 570 & $95.6 \%$ & 96 & $83.5 \%$ & 666 & $93.7 \%$ & \multirow{2}{*}{$<0.001$} \\
\hline & Yes & 26 & $4.4 \%$ & 19 & $16.5 \%$ & 45 & $6.3 \%$ & \\
\hline \multirow{2}{*}{ CAD } & No & 550 & $92.3 \%$ & 92 & $80.0 \%$ & 642 & $90.3 \%$ & \multirow{2}{*}{$<0.001$} \\
\hline & Yes & 46 & $7.7 \%$ & 23 & $20.0 \%$ & 69 & $9.7 \%$ & \\
\hline \multirow{2}{*}{$\mathrm{AF}$} & No & 587 & $98.5 \%$ & 109 & $94.8 \%$ & 696 & $97.9 \%$ & \multirow{2}{*}{0.011} \\
\hline & Yes & 9 & $1.5 \%$ & 6 & $5.2 \%$ & 15 & $2.1 \%$ & \\
\hline \multirow{2}{*}{ CRF } & No & 558 & $93.6 \%$ & 103 & $89.6 \%$ & 661 & $93.0 \%$ & \multirow{2}{*}{0.119} \\
\hline & Yes & 38 & $6.4 \%$ & 12 & $10.4 \%$ & 50 & $7.0 \%$ & \\
\hline \multirow{2}{*}{ CND } & No & 560 & $94.0 \%$ & 101 & $87.8 \%$ & 661 & $93.0 \%$ & \multirow{2}{*}{0.019} \\
\hline & Yes & 36 & $6.0 \%$ & 14 & $12.2 \%$ & 50 & $7.0 \%$ & \\
\hline \multirow[t]{3}{*}{ Total } & & 596 & 100 & 115 & 100 & 711 & 100.0 & \\
\hline & & \multicolumn{2}{|c|}{ IU } & \multicolumn{2}{|c|}{ ICU } & \multicolumn{2}{|c|}{ Total } & \\
\hline & & Median & IQR & Median & IQR & Median & IQR & \\
\hline Age & & 61 & $47-74$ & 75 & $65-81$ & 64 & $49-76$ & $<0.001$ \\
\hline \multicolumn{9}{|c|}{$\begin{array}{l}\text { IU: Inpatient unit, ICU: Intensive care unit, COPD: Chronic Obstructive Pulmonary Disease, DM: } \\
\text { Diabetes Mellitus, HT: Hypertension, CHF: Congestive Heart Failure, CAD: Coronary Artery } \\
\text { Disease, AF: Atrial Fibrillation, CRF: Chronic Renal Failure, CND: Chronic Neurological Disease Sig: } \\
\text { Significance }\end{array}$} \\
\hline
\end{tabular}

When ICU groups were compared according to the measurements of PLT, MPV, MPV/PLT used in the study, there was a significant difference for PLT and MPV, but no significant difference for MPV/PLT (Table 2). 
Table 2. Comparison of PLT, MPV, MPV / PLT values according to the intensive care needs of COVID-19 patients

\begin{tabular}{|c|c|c|c|c|c|c|c|c|}
\hline Variables & ICU & $\mathbf{N}(711)$ & Mean Rank & Mann-Whitney U & $25^{\text {th }}$ & Median & $75^{\text {th }}$ & $\mathbf{p}$ \\
\hline \multirow{2}{*}{$\operatorname{PLT}\left(10^{3} / \mathrm{uL}\right)$} & $\mathrm{NO}$ & 596 & 349.01 & \multirow{2}{*}{30101.5} & \multirow{2}{*}{158000} & \multirow{2}{*}{202000} & \multirow{2}{*}{254000} & \multirow{2}{*}{0.039} \\
\hline & YES & 115 & 392.25 & & & & & \\
\hline \multirow{2}{*}{$\operatorname{MPV}\left(\mu \mathrm{m}^{3}\right)$} & NO & 596 & 348.78 & \multirow{2}{*}{29965} & \multirow{2}{*}{7.90} & \multirow{2}{*}{8.60} & \multirow{2}{*}{9.40} & \multirow{2}{*}{0.033} \\
\hline & YES & 115 & 393.43 & & & & & \\
\hline \multirow{2}{*}{ MPV / PLT } & NO & 596 & 359.60 & \multirow{2}{*}{32122} & \multirow{2}{*}{32.90} & \multirow{2}{*}{42.39} & \multirow{2}{*}{58.39} & \multirow{2}{*}{0.287} \\
\hline & YES & 115 & 337.32 & & & & & \\
\hline
\end{tabular}

In the CHAID analysis made based on the hypothesis that MPV may affect the ICU requirement in relation to age, thresholds 58 and 73 for age are important threshold values determined by CHAID analysis. For patients aged 58 and younger, the cut-off value of MPV of 8.3 was also obtained as the output of the CHAID analysis. ICU requirement is calculated as $6 \%$ for those who aged 58 and younger, $14.8 \%$ for those who aged 58 to 73 , and $30.6 \%$ for those who older than 73 . For those who 58 years and younger, the ICU requirement was $0.8 \%$ for those whose MPV value was less than 8.3, while it was determined that for those over 8.3 , it was $9.8 \%$ (Figure 1).

Chi-square and Fisher's Exact tests were performed in order to analyze the relationship of the threshold value of 8.3 for MPV with the ICU requirement after divided the study population into 2 classes (as Younger Group and Older Group). For the Younger group, based on the 8.3 threshold value of MPV, a significant difference was found in terms of ICU requirement $(\mathrm{p}=0.002)$, while no significant difference was found in the patients with Older group in terms of ICU requirement $(\mathrm{p}=0.558)$ (Table 3$)$.

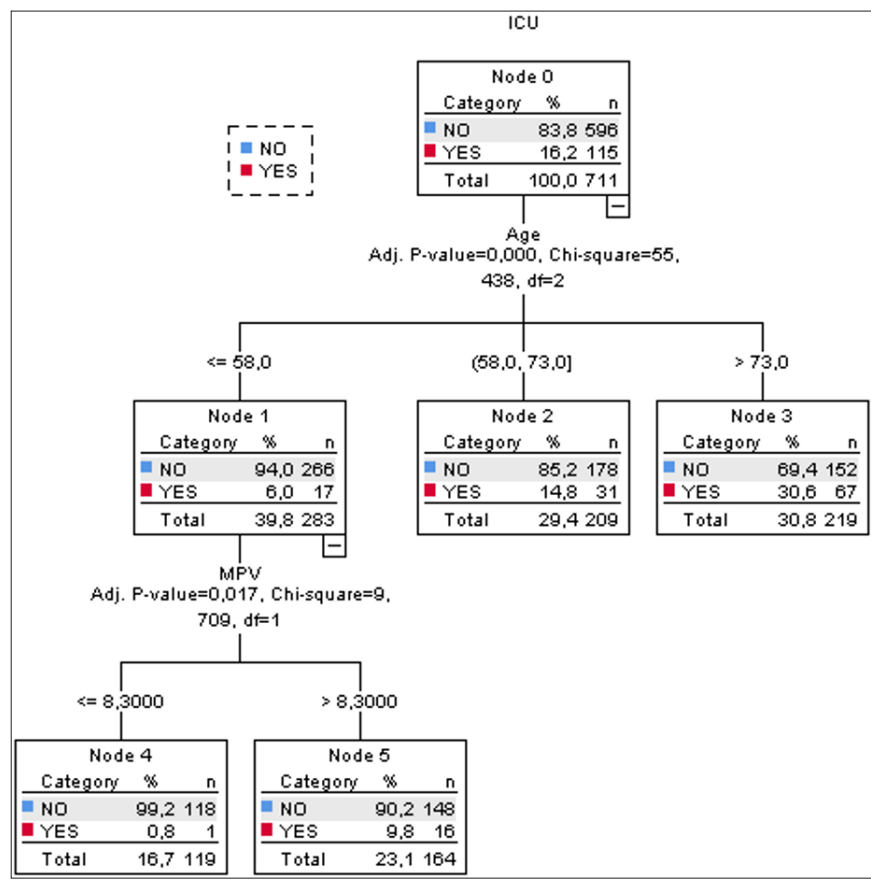

Figure 1. CHAID chart with MPV and age variables in terms of ICU requirement in COVID-19 patients
Table 3. The relationship of the threshold value of $8.3 \mathrm{MPV}$ with the need for intensive care in COVID-19 patients according to the age limit of 58

\begin{tabular}{|cccccc|}
\hline & & \multicolumn{2}{c}{ ICU } & Total & Significance \\
\cline { 3 - 6 } & & No & Yes & n & p \\
\hline \multirow{3}{*}{$\leq 58$} & $\leq 8.3$ & $118(99.2 \%)$ & $1(0.8 \%)$ & 119 & \\
& $>8.3$ & $148(90.2 \%)$ & $16(9.8 \%)$ & 164 & $0.002^{*}$ \\
& $\mathrm{n}$ & 266 & 17 & 283 & \\
& $\leq 8.3$ & $133(78.7 \%)$ & $36(21.3 \%)$ & 169 & \\
$>58$ & $>8.3$ & $197(76.1 \%)$ & $62(23.9 \%)$ & 259 & 0.558 \\
& $\mathrm{n}$ & 330 & 98 & 428 & \\
\hline
\end{tabular}

ROC analysis was performed to describe the accuracy of 8.3 threshold value of MPV for predicting ICU requirement in patients aged 58 years and younger (Younger group). By ROC analysis, it was calculated that AUC 0.692 (0.591-0.794), sensitivity 94.1, specificity 44.4 , positive predictive value $9.8 \%$, negative predictive value $99.2 \%$ and YJI 0.39 . The $\mathrm{p}$ value for the AUC value was calculated as 0.008 (Table 4, Figure 2).

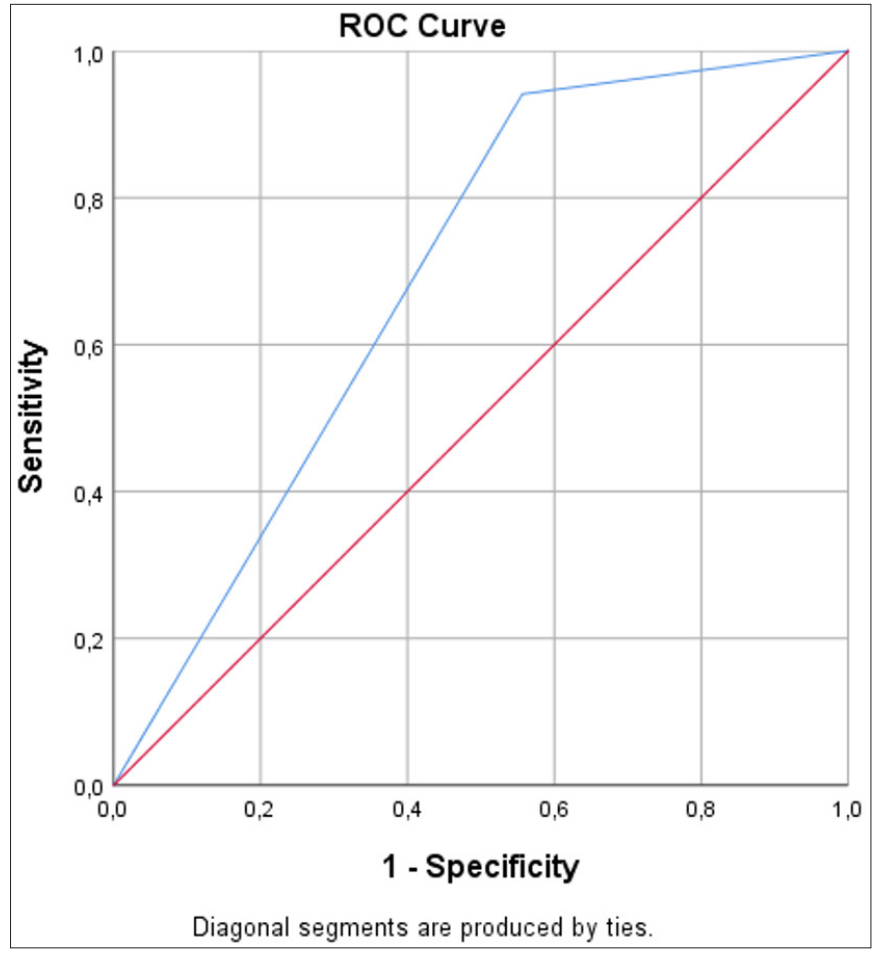

Figure 2. ROC graph for MPV threshold of 8.3 in terms of ICU requirement in COVID-19 patients under 58 years of age 


\begin{tabular}{|c|c|c|c|c|c|c|c|c|}
\hline AUC & $95 \% \mathrm{CI}^{*}$ & S. E. & $\mathrm{p}$ & Sensitivity & Spesifity & PPV & NPV & YJI \\
\hline 0.692 & $0.591-0.794$ & 0.052 & 0.008 & $94.1 \%$ & $44.4 \%$ & $9.8 \%$ & $99.2 \%$ & 0.39 \\
\hline
\end{tabular}

\section{DISCUSSION}

In our study, we concluded that advanced age, MPV and PLT values will have important predictive values in COVID-19 patients. In addition, CHAID analysis was applied and accordingly, it obtained the conclusion that 8.3 threshold value of MPV under 58 years old could predict the ICU requirement.

MPV is a simple, inexpensive and easily obtainable biomarker of platelet function and can be measured in almost all laboratories. It shows a correlation with platelet volume, platelet function and activation (12). Platelets, In addition, to primary hemostatic functions, it plays a role in the pathogenesis of infectious diseases (13). The some studies in the literature has been reported that megakaryocytes can be affected by cytokines such as IL- 3 and IL- 6 and this may lead to the production of more and more reactive platelets (14). In our study, we concluded that there is a positive correlation between high MPV and ICU requirement. The pathophysiological mechanism of MPV for predicting the prognosis of patients with COVID-19 is not clear, but there are opinions reported on this issue in the literature. For example, under the condition of inflammation, platelet production will increase due to the increased synthesis of thrombopoietin mediated by a wide variety of cytokines (15). MPV reflects the metabolism and proliferation of megakaryocytes and platelet production in the bone marrow. Initially, when infection occurs, the release of many inflammatory cytokines (such as interleukin-1 (IL1), IL-3 and IL-6 and tumor necrosis factor- $\alpha$ (TNF- $\alpha$ )) increases and thrombopoietin increases and expression of young platelets in the bloodstream, It causes an increase of MPV (16). Additionally, after stress-induced platelet destruction, the decrease in platelet count further stimulates the megakaryocyte to produce a large number of platelets, resulting in an increase of MPV. Ultimately, it has been reported that, low prognosis in patients with decreased platelet count and high MPV may be associated with oxidative stress in activated platelets, increased risk of thrombosis and apoptosis (17).

In our study, it is seen that there is a positive correlation between advanced age and ICU requirement. As a matter of fact, many studies in the literature have reported that advanced age is associated with higher mortality and ICU admission in COVID-19 patients (18-20).

In a study recently reported from Turkey, a group of COVID-19 patients were compared with a healthy population in the pediatric age group. It has been emphasized that those with COVID-19 have higher MPV and lower lymphocyte values compared to the healthy group (21). In our study, MPV was found to be significant in predicting the ICU requirement. However, in the CHAID analysis, we concluded that this success is useful in patients aged 58 years and younger. This shows that MPV is not useful for determining the ICU requirement in the geriatric age group.

There are some limitations in our study. First, our study was conducted on a relatively small population from a single center and needs to be confirmed with a larger, multicenter cohort. In addition, due to the retrospective nature of our study, data was obtained from an electronic registration system, which might create limitations due to providing incomplete or outdated information.

\section{CONCLUSION}

Advanced age, high MPV and PLT values are associated with the ICU requirement in COVID-19 patients. The 8.3 threshold value of MPV can be used as one of the parameters determining the ICU requirement in relatively young patients. In the geriatric age group, it is not useful to use MPV to determine the ICU requirement. Multicenter studies with a large number of patients are needed to present the strength of the results of our study more clearly.

\section{ETHICAL DECLARATIONS}

Ethics Committee Approval: The study was carried out with the permission of Research Ethics Committee of Kartal Dr. Lütfi Kurdar City Hospital (Date: 29.03.2021, Decision No: 2021/514/198/28).

Informed Consent: Because the study was designed retrospectively, no written informed consent form was obtained from patients.

Referee Evaluation Process: Externally peer-reviewed.

Conflict of Interest Statement: The authors have no conflicts of interest to declare.

Financial Disclosure: The authors declared that this study had received no financial support.

Author Contributions: All of the authors declare that they have all participated in the design, execution, and analysis of the paper and approved the final version. 


\section{REFERENCES}

1. Li Q, Guan X, Wu P, et al. Early transmission dynamics in Wuhan, China, of novel coronavirus-infected pneumonia. $\mathrm{N}$ Engl J Med 2020; 382: 1199-207.

2. Zhu N, Zhang D, Wang $\mathrm{W}$, et al. A novel coronavirus from patients with pneumonia in China, 2019. N Engl J Med 2020; 382: 727-33.

3. Lu R, Zhao X, Li J, et al. Genomic characterisation and epidemiology of 2019 novel coronavirus: implications for virus origins and receptor binding. Lancet 2020; 395: 556-74.

4. Chen N, Zhou M, Dong X, et al. Epidemiological and clinical charac-teristics of 99 cases of 2019 novel coronavirus pneumonia in Wuhan, China: a descriptive study. Lancet 2020; 395: 507-13.

5. Chan KW, Wong VT, Tang S. COVID-19: an update on the epidemio-logical, clinical, preventive and therapeutic evidence and guidelines of integrative Chinese-western medicine for the management of 2019 novel coronavirus disease. Am J Chin Med 2020; 48: 737-62.

6. Huang C, Wang Y, Li X, et al. Clinical features of patients infected with 2019 novel coronavirus in Wuhan. China. LANCET 2020; 395: 497-506.

7. Gençay I, Büyükkoçak Ü, Ateş G, Çağlayan O. Mean platelet volume and platelet distribution width as mortality predictors in intensive care unit. J Health Sci Med 2020; 3: 51-5.

8. Tajarernmuang $\mathrm{P}$, Phrommintikul A, Limsukon A, Pothirat $\mathrm{C}$, Chittawatanarat $\mathrm{K}$. The role of mean platelet volume as a predictor of mortality in critically ill patients: a systematic review and me-ta-analysis. Crit Care Res Pract 2016; 2016: 1-8.

9. Seyhan AU, Doğanay F, Yılmaz E, Aydıner Ö, Ak R, Tekol SD. The comparison of chest CT and RT-PCR during the diagnosis of COVID-19. J Clin Med Kazakhstan 2021; 18: 53-6.

10.Kayri M , Boysan M . Using Chaid Analysis in Researches and an Application Pertaining to Coping Strategies. AÜUBFD 2007; 40: 133-49.

11. Fluss R, Faraggi D, Reiser B. Estimation of the Youden Index and its associated cutoff point. Biom J 2005; 47: 458-72.

12. Martin JF, Trowbridge EA, Salmon G, Plumb J. The biological significance of platelet volume: its relationship to bleeding time, platelet thromboxane B2 production and megakaryocyte nuclear DNA con-centration. Thromb Res 1983; 32: 443-60.

13. Becchi C, Al Malyan M, Fabbri LP, Marsili M, Boddi V, Boncinelli S. Mean platelet volume trend in sepsis: is it a useful parameter? Minerva Anestesiol 2006; 72: 749-56.

14. Kaser A, Brandacher G, Steurer W, et al. Interleukin-6 stimulates thrombopoiesis through thrombopoietin: role in inflammatory thrombocytosis. Blood 2001; 98: 2720-5.

15. Gorelik O, Izhakian S, Barchel D, et al. Prognostic significance of platelet count changes during hospitalization for communityac-quired pneumonia. Platelets 2017; 28: 380-6.

16.Lee JH, Park M, Han S, Hwang JJ, Park SH, Park SY. An increase in mean platelet volume during admission can predict the prognoses of patients with pneumonia in the intensive care unit: a retrospec-tive study. PLoS One 2018; 13: e208715.

17. Chu SG, Becker RC, Berger PB, et al. Mean platelet volume as a pre-dictor of cardiovascular risk: a systematic review and metaanalysis. J Thromb Haemost 2010; 8: 148-56.

18. Imam Z, Odish F, Gill I, et al. Older age and comorbidity are independent mortality predictors in a large cohort of 1305 COVID-19 patients in Michigan, United States. J Int Med 2020; 288: 469-76.

19. Russell TW, Hellewell J, Jarvis CI, et al. CMMID COVID-19 working group. Estimating the infection and case fatality ratio for coronavirus disease (COVID-19) using age-adjusted data from the outbreak on the Diamond Princess cruise ship, February 2020. Eurosurveillance 2020; 25: 2000256.
20.Doğanay F, Elkonca F, Seyhan AU, Yılmaz E, Batırel A, Ak R. Shock index as a predictor of mortality among the COVID-19 patients. Am J Emerg Med 2021; 40: 106-9.

21.Gumus H, Demir A, Yükkaldıran A. Is mean platelet volume a predictive marker for the diagnosis of COVID-19 in children? Int J Clin Pract 2020: e13892. 